\title{
Commemorating Judit
}

\author{
Tibor Braun ${ }^{1,2} \cdot$ Wolfgang Glänzel ${ }^{2,3} \cdot$ András Schubert $^{2}$
}

Received: 13 March 2020 / Published online: 26 April 2020

(c) Akadémiai Kiadó, Budapest, Hungary 2020

She was certainly addressed zillion times as Doctor Bar-Ilan, Professor Bar-Ilan or maybe Frau Professor, but for all of us who knew her more closely, she could not be anything else but Judit. She was Judit in Hungary, where she was born, in Israel, where she lived and all over the world, where she brightened any event with her modest, yet radiating personality.

She will be painfully missed but will also healingly stay with us forever. Her inquiring look, her encouraging smile, her firm but never hurtful opinions.

Her writings were extremely clear and economic. While compiling 100 memorable sentences from the journal Scientometrics for its jubilee (100th) volume, it was exceptionally difficult to tear a single sentence from her texts without severely damaging their contextual integrity.

In the present issue, a collection of research papers is presented, each specifically dedicated to Judit's memory. Some of them are directly targeting Judit's oeuvre, others were inspired by concepts, ideas closely or loosely related to her works. What is common in each is that all authors of the issue were motivated by their deepest regard to Judit both as an erudite colleague and as an awesome personality.

Some of our colleagues submitted beside or instead of a research paper, some personal appreciations, memories or stories. In the rest of this Preface, these texts are compiled as personal farewell to Judit.

Isidro F. Aguillo, Cybermetrics Lab IPP-CSIC, Madrid, Spain

I would like to share a personal anecdote about my relationship with Judit. I first met her during the Jerusalem ISSI's conference. Since then we had a wonderful relationship linked to our mutual interest in web indicators. We shared methods and findings for more than 2 decades and even I have the honor of co-authoring with her what is today my most cited paper about university ranking. Our mutual interests and passion for metrics is clearly demonstrated by a small contest we developed during years: Every time we met at conferences or project meetings, we shared the number of different countries we already visited. Almost a tie (over 50 countries each), we devoted a lot of time establishing the "rules": A no longer existing country, but visited when it was (East Germany) is OK, but not going beyond the airport in a flight stop was not accepted in the list. A funny and completely

Wolfgang Glänzel

wolfgang.glanzel@kuleuven.be

1 Institute of Chemistry, Eötvös Loránd University (ELTE), Budapest, Hungary

2 Library and Information Center of the Hungarian Academy of Science, Budapest, Hungary

3 ECOOM and Department of Management, Strategy and Innovation, KU Leuven, Louvain, Belgium 
irrelevant exchange that we enjoyed for many years and help us to reinforce our friendship. Every time I visit a "new" country I will devote a few seconds to her.

\section{Noa Aharony, Department of Information Science, Bar-Ilan University, Ramat-Gan, Israel}

It is strange to think that Judit is not with us anymore; it is odd to talk about her in the past tense. She was my friend, mentor and professional model.

Judit was an excellent, clever, intelligent scholar as well as an honest, modest, curious, diligent and a nice person. She was very kind, but in the same time firm. Her students and colleagues knew that she was always ready to assist, basing her advice on her wisdom, intelligence, large experience, and always with a lot of patience.

On a very personal note, Judit was my mentor and set me a professional example of a great researcher and a human being. Her enthusiasm for research has inspired me and I consider myself lucky to have had a chance to work with her and to learn from her. I miss our long conversations and consultations concerning professional issues as well as private ones.

Judit is already missed by her students and peers worldwide.

May her memory be for a blessing.

Péter Jacsó, Information and Computer Sciences Department at the University of Hawai 'i at Mānoa, Honolulu, HI, USA

Judit has left us way soon, but she did leave for us a gold mine of scholarly articles, conference papers, book chapters about bibliometrics, scientometrics and informetrics. She had a master degree in mathematics and a doctoral degree in computer science, and certainly could have earned also the highest degree in library and information science (LIS) by virtue of doing outstanding research, providing substantial services for ASIS\&T, assisting the organization and management of conferences by peer reviewing submitted papers and selecting topics and speakers for workshops, tutorials to be held before and after the conferences, previewing, and editing manuscripts among others for Scientometrics, Journal of Informetrics, Online Information Review. Her sitting on the board of so many committees and editorial was much more like surfing on the editorial board to proceed.

On top of these she was teaching courses and was also the chair of the Information Science Department at Bar-Ilan University. Just a few days before her passing her website (https://is.biu.ac.il/en/judit) was updated and reflected the many managerial tasks that she had been doing on top of teaching. On the side she wrote books and hundreds of journal articles and conference papers on scientometrics and informetrics, which were not only widely cited but also very widely used in library and information science courses from North America to South Africa.

It would be most appropriate to establish a Bar-Ilan Award to be sponsored by ASIS\&T in support of those junior LIS and IS faculty members who could offer the resumption of workshops and tutorials on current and future issues of bibliometrics, scientometrics, and informetrics in recognition of the very impressive research done by Judit in the past 30 years.

The reading list with hot links is practically available. This would be the best way to say: Shalom, dear Judit

\section{Henk F. Moed, Sapienza University of Rome, Italy}

Judit Bar-Ilan was one of the most important scholars in the domain of information science, and one of the finest colleagues I have ever worked with. The most notable 
characteristic of her scholarly work and impact is, in my view, the breadth of the topics she studied. She was active in the fields of library science, communication science, computer science, bibliometrics, informetrics, and research evaluation, and often in the interface between these fields.

Her research findings were not only published in journals, but also in books and conference proceedings. She was a regular participant in international conferences, meetings and expert groups, and delivered important presentations in at all the conferences that I attended through the years.

An analysis of Judit's publications results in an extensive list of research topics she has been studying during the past three decades. The list, although not comprehensive, serves as illustration of the breath of Judit's work:

SEARCH ENGINESI SEARCH ALGORITHMS I ASSESSMENT OF INFORMATION QUALITYI SYSTEM SECURITYI INFORMATION NEEDSI ONTOLOGIESI INFORMATION RECEPTION I INFORMATION USER SURVEYSI LITERATURE DATABASESI DATABASE COMPARISONSI GOOGLE SCHOLARI WIKIPEDIAI ALTMETRICSI RESEARCH BLOGSI INTERNET USEI ELECTRONIC PUBLISHING| WEBOMETRICSI CITATION ANALYSISI STATISTICAL PROPERTIES OF INDICATORSI UNIVERSITY RANKINGSI NEW INDICATORS INCLUDING CHI-INDEXI THE APPLICATION OF BIBLIOMETRIC INDICATORSI RESPONSIBLE METRICSI RETRACTIONSI SCHOLARLY COLLABORATION AND MOBILITYI ACADEMIC CAREERSI NETWORK ANALYSISI COMPUTERS AND HUMAN BEHAVIOURI INFORMETRIC THEORIES.

In addition, the analysis of Judit's work reveals the considerable increase in the number of articles she published, especially in the last 5 years of her life with a notable peak in the number of publications in 2018.

Judit studied information constructs or products that were visible and debated among a wide audience and had an impact reaching far beyond the boundaries of the information science field. Two good examples are her research on the "h-index" and "Google Scholar". She went further and combined the two subjects in one of her most impactful papers "Which h-index? - A comparison of WoS, Scopus and Google Scholar".

Judit was very much involved in studying users of information-scientific products, their information needs, and sociological and psychological aspects of their behaviour, which went beyond the technical aspects of search algorithms and indicators. A good example is her article entitled "Psychological factors behind the lack of participation in online discussions".

Judit gave attention to the social context and the future of our field, which was published in several articles such as "Informetrics at the beginning of the 21 st century-A review", and her important role in the study "Academic Careers Understood through Measurement and Norms", focusing on how research evaluation processes can be improved and enhanced.

Judit was always bright and alert. Her ideas and opinions were highly appreciated by her colleagues. I have no doubt that everyone who was familiar with her work, like myself, had moments at which, when confronted with a complex research problem, ask, "I wonder what Judit would say about this issue", or, "I must make sure that I talk with Judit at the next conference, so that I can ask her opinion".

We will all miss her detailed, practical knowledge of the ins and outs of many of our concepts and products, her guidance and her thinking of the future in our field.

References

Bar-Ilan, J. (2008). Which h-index? A comparison of WoS, Scopus and Google Scholar. Scientometrics, 74(2), 257-271. 
Bar-Ilan, J. (2008). Informetrics at the beginning of the 21 st century-A review. Journal of Informetrics, 2(1), 1-52.

Academic Careers Understood through Measurement and Norms. EU Seventh Framework Program, 2007. https://cordis.europa.eu/project/rcn/97240/reporting/en

\section{Bluma C. Peritz, Professor Emerita, Hebrew University of Jerusalem, Israel}

Judit passed away 11 days after her 61 birthday, after a long suffering and a very courageous fight for life.

We used to celebrate out birthdays together, I sent her the favorite flowers, and her telephone call to thank me, I did not recognize her voice and we both cried.

Born in Budapest, she immigrated with her parents to Israel at the age of 15.

My relations with Judit as a colleague, friend and partner in research go back now for many years.

As director of the School of Library and Information Studies of the Hebrew University of Jerusalem I recruited her in 1991 as a faculty member. She attended my seminar in Bibliometrics and was fascinated, as well as classification, thesaurus construction and metadata.

Judit, with a master degree in Mathematics and $\mathrm{PhD}$ in Computer Science, was given the tasks to develop for the School: Information Systems, Information Retrieval from on-line Databases and advanced teaching technologies.

Judit started her academic career at the Hebrew University of Jerusalem at the School of Libraries and Information Studies, her first line of research was in Bibliometrics, she accomplished her missions with success and the School and students benefitted greatly from her work and motivation. She was a faculty member at the Hebrew University for 14 years.

At the first conferences of ISSI she participated, I introduced her to the main researchers in the field already known by her from their publications. She was fascinated, like a child, having new toys and new relations.

The ISSI Society was founded in Berlin in 1993, the conferences took place every second year. Judit started to participate right after her integration at the School of Library and Information Studies. At every conference she was there already with original ideas.

In 2004 she was invited by the Department of Information Science of the Bar-Ilan University as head of the Department, she served in this capacity for a few years. In 2010 she was granted full Professorship.

By that time, she already gave up her dream to be a famous mathematician, to become a very famous and respected Scientometrician.

Her research was in Information Science, especially Scientometrics, which became her main interest. In the field of Scientometrics she was there with her original research at almost every step of the development of the field, from Bibliometrics to Scientometrics, Webometrics, Hirsch Index and lately Altmetrics from 2011.

She guided a considerable number of PhD students, some became faculty members.

She has a remarkable list of publications, chapters in books, published in the most prestigious and cited Journals of the profession. She presented papers at almost every conference in the field.

Her over 250 publications with a total of 5180 Google Scholar citations show a highly productive and outstanding career. 
Judit served on the editorial boards of many scientific professional journals, like: Scientometrics, American Journal of Information Science and Technology, Journal of Data and Information Science, and lately she initiated a new special journal, Altmetrics.

She looked out to other disciplines trying to find connections, to theoretically, practical and methodological aspects who can be applied to Scientometrics and vice versa.

One of her great contributions to Information Science was through search engines evaluations, bibliometrics, Google Scholar analysis and lately Altmetrics.

She applied bibliometric techniques when the Internet and World Wide Web started to be central for retrieving information, this is when she started her research in Information Retrieval.

In addition to her on-going active research Judit contributed much to Information Science. She was a member of ASIST and SIGMET as well as three other international societies and five national groups. She served on seven editorial boards and has served on dozens of program committees. She was a member of the Israeli Science Foundation of the Israeli Academy of Sciences for evaluation of research in her field.

Judit's another great contribution to Information Science was also by introducing practical and theoretical knowledge in the field.

She believed in collaboration on International and national levels and was involved in many co-authoring studies.

In 2017 Judit was awarded the Derek de Solla Price Medal, and in 2018 the American Society for Information Science and Technology award.

She was a very quiet warm person, highly motivated, with a remarkable intellectual curiosity.

She is survived by her parents, husband, three children and three grandchildren.

Her passing away is a great loss for her family, profession and colleagues.

She will be remembered with great admiration and respect by all of us.

For me, is losing a great friend and a gifted daughter.

\section{Eric Zimmermann, The Interdisciplinary Center, Herzliya, Israel}

Judit was my $\mathrm{PhD}$ supervisor, having also studied under Prof. Sara Fine (who died prematurely as well). She was no less than a brilliant scholar, driven by curiosity, with an eye for detail unmatched by other lecturers during my studies. She was a true academic giant in her field, a methodical researcher, kind but firm, and a true inspiration to her peers and students. I learned a tremendous amount from her; the strength of my dissertation was a true reflection of her dedicated guidance. Some years after my studies, Judit invited me to Brussels to participate in the final event of a project. To see how she injected intelligence into the discussions and to witness how she was treated as a scholar and a person gave me great personal and professional satisfaction. Judit is sorely missed. 